\title{
A study on the recent 20 years' herbal medication rules and syndromes distribution in TCM treatment of Diabetic Nephropathy by Data mining
}

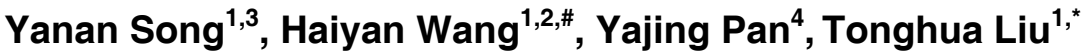 \\ ${ }^{1}$ Beijing University of Chinese Medicine, Beijing 100029, China; ${ }^{2} J o s l i n$ Diabetes Center, Harvard \\ Medical School, Boston, 02115, United States; ${ }^{3}$ Boston Children Hospital, Boston, 02115, United States; \\ ${ }^{4}$ University of California, Los Angeles, 90095, United States
}

\#Co-first author, contribute equally

${ }^{*}$ Corresponding author: Prof. Tonghua Liu, Email: thliu@vip.163.com

Received May 28, 2019; Accepted August 17, 2019

\begin{abstract}
Aim: To study the recent 20 years' herbal medication rules and syndromes distribution in TCM treatment of diabetic nephropathy based on modern literature.

Methods: We used SPSS18.0 and SPSS Modeler14.1 for data analysis. The descriptive analysis and cluster analysis were performed by SPSS 18.0; the association rules analysis with the Apriori algorithm was performed by SPSS Modeler14.1.
\end{abstract}

Results: 274 TCM formulas were obtained after screening. The 5 most frequently used Chinese herbal medicines are milkvetch root, Indian bread, common yam rhizome, danshen root, Asiatic cornelian cherry fruit; The 5 most common syndromes of DN are deficiency Qi and Yin, obstruction of collaterals by blood stasis, deficiency of liver and kidney, damp-heat stasis obstruction, Yin asthenia generating intrinsic heat; the 5 most common pathological factors are Yin deficiency, blood stasis, Qi deficiency, endogenous heat and phlegm. In association rules analysis, we displayed association rules among herbs of confidence greater than $85 \%$ and support greater than $15 \%$. By clustering, we obtained 12 sets of core couplet herbs.

Conclusion: The syndrome differentiation of DN is not fixed but dynamic development progress. The syndromes and prescription regularities in the current 20 years are systematically summarized by data mining, which provides data support for clinical differentiation and further researches.

Key Words: Diabetic Nephropathy; Traditional Chinese medicine; syndromes distribution; Herbal medication rules

\section{INTRODUCTION}

Diabetic nephropathy (DN) is a widely recognized microvascular complication of diabetes and the largest single cause of the end-stage renal disease (ESRD), which is still a major contributor to morbidity and mortality of diabetic patients worldwide. ${ }^{1-4}$ It is estimated that diabetes will reach 366 million by 2030, compared with more than 100 million for diabetic nephropathy. ${ }^{4,5}$ According to the data of American Diabetes Association, diabetes mellitus has a major impact on the development of DN. DN occurs in $20 \%$ to $40 \%$ of all patients with type 2 diabetes mellitus, accounting for approximately $50 \%$ of cases in the developed countries. ${ }^{6}$

Clinical manifestations of DN include an initial increase in glomerular filtration (GFR), proteinuria, increased creatinine levels, and eventually decreased $\mathrm{GFR}^{7}$. The major pathological alterations in DN include excessive accumulation and deposition of extracellular matrix, leading to expansion of mesangial matrix, thickening of glomerular basement membrane and tubulointerstitial fibrosis. ${ }^{5}$ Based on the pathogenic factors of $\mathrm{DN}$, a large number of novel treatment options have arisen from experimental studies, including intensive glycemic control, precise blood pressure control, optimal RAAS blockade with ACEI/ARB, lifestyle

This is an open access journal, and articles are distributed under the terms of the Creative Commons Attribution-NonCommercial-ShareAlike 4.0 License, which allows others to remix, tweak, and build upon the work non-commercially, as long as appropriate credit is given and the new creations are licensed under the identical terms.

For reprints contact: weda-h@weda-h.org

How to cite this article: Song YN, Wang HY, Pan YJ, Liu TH. A study on the recent 20 years' herbal medication rules and syndromes distribution in TCM treatment of Diabetic Nephropathy by Data mining. J ADV HEALTH 2019; 1(3): 161-171. 
modifications such as exercise and dietary restrictions, and a lot of novel agents. ${ }^{1,8}$ In spite of the widespread application of numerous therapeutic approaches focusing on the management of factors mentioned above, the portion of ESRD due to DN still remains high. The interventions in general clinical use cannot efficiently slow or reverse the progression of nephropathy. ${ }^{7}$ Therefore, interventions that could optimally delay the development of DN are required.

Traditional Chinese medicine (TCM) has been widely used in the treatment of diabetes and its complications for a long time. ${ }^{9-11}$ Up to now, there have been many experiments focusing on the treatment of diabetes and its complications with traditional Chinese medicine (TCM) because of less toxicity and/or side effects. ${ }^{12,13}$ From ancient times to the present, diabetic nephropathy has many diseases name in TCM, and it is equivalent to the category of "urine turbidity", "edema", "kidney fatigue", "Guan-ge" and "kidney-elimination" in TCM. According to traditional Chinese medicine, the basic pathogenesis of DN is the deficiency of both Qi and Yin, and the deficiency of both Qi and Yin throughout the development of DN. The main disease location is in the kidney, and is closely related to the liver, lung and spleen as well. ${ }^{10}$

To the present, little systematic research was done exploring the TCM syndrome distribution and herbal medication rules of DN. In this study, 274 prescriptions from the literature of TCM treatment of DN published in the last 20 years (1 January, 1998 - 30 June, 2019) were investigated, aiming to explore the TCM syndrome distributions and medication rules of TCM treatment for DN and shine valuable insight for TCM treatment of DN.

\section{MATERIAL AND METHODS}

\section{Data sources}

All the formulas were acquired from the literature of TCM treatment of DN published from 1 January, 1998 to 30 June, 2019 from both Chinese and English online databases. Set Traditional Chinese medicine or Chinese medicine or herbal medicine or herb or TCM or Chinese materia medica, and diabetic nephropathy or $\mathrm{DN}$ or diabetic kidney as the keyword, we searched the Chinese language databases consist of the China National Knowledge Infrastructure (CNKI) database, Wanfang database, the VIP Chinese Science and Technique Journals database. The English language databases we searched consist of PubMed, Embase, Web of Science and Cochrane Library.

\section{Literature screening}

\section{Inclusion criteria :}

1. Patients were clearly diagnosed as DN by Western medicine, the diagnosed criteria were reference to the statement declared by American Diabetes Association ${ }^{14}$.

2. TCM treatment was taken as a part of the overall DN treatment, and the treatment was effective reference to "Chinese and Western medicine diagnosis and treatment of diabetes and its complications" guideline.

3. TCM formula composition was clearly recorded.

4. Only oral formulas were included.

\section{Exclusion criteria :}

1. Literature with no exact diagnosis of DN by Western Medicine.

2. Formulas for external application.

\section{Data standardization}

The syndromes and pathological factors were standardized according to the National Standards of the People's Republic of China: TCM clinical diagnosis and treatment terminology.

\section{Data entry}

The selected prescriptions were entered into Excel 2007 manually by two researchers independently. After the entry was completed, the data was double-checked to ensure accuracy.

\section{Software used}

We used SPSS18.0and SPSS Modeler14.1 for data analysis. The descriptive analysis and cluster analysis was performed by SPSS 18.0; the association rules analysis with the Apriori algorithm was performed by SPSS Modeler14.1.

\section{RESULTS}

After screening, 274 formulas were obtained. The meaningful results of frequency analysis, association rule analysis and cluster analysis were retained, and the repetitive and redundant rules were not retained.

\section{Frequency analysis}

According to the frequency, Table I shows the herbs with a frequency greater than or equal to 20; Table II shows the frequency of DN stages in literature Table III shows the frequency of the syndrome; Table IV frequency of the syndrome elements.

\section{Frequency analysis of the herbs prescribed}

274 prescriptions, including 213 herbs were obtained in this study; the total herb use frequency was 3015 . We listed herbs with a frequency greater than or equal to 20 in Table I.

As it is shown in Table I, the most frequently used herbs are Milkvetch root(Radix Astragali seu Hedysari), Indian bread(Poria), Common yam rhizome(Rhizoma Dioscoreae), Danshen root(Radix Salviae Miltiorrhizae), Asiatic cornelian cherry fruit(Fructus Corni), Unprocessed Rehmannia root(Radix Rehmanniae Recens), Chinese angelica(Radix Angelicae Sinensis), Rhubarb root and rhizome(Radix et Rhizoma Rhei), Oriental water plantain rhizome (Rhizoma Alismatis), Largehead atractylodes rhizome(Rhizoma Atractylodis Macrocephalae), Sichuan lovage rhizome(Rhizoma Ligustici Chuanxiong), Prepared rehmannia root(Radix Rehmanniae Preparata), Tangshen(Radix Codonopsis), Tree peony root bark (Cortex Moutan Radicis), Heterophylly falsestarwort root(Radix Pseudostellariae).

\section{Frequency of DN stages}

Considering the inconsistency of staging diagnostic criteria for DN in the literature, the investigators re-delineated the medical records in each literature to "early-stage (I, II, III)", "medium stage (IV)" and "end-stage (V)" based on the Mogensen staging criteria ${ }^{15}$ and the TCM DN staging criteria put forward by Professor Lv Renhe ${ }^{16}$.

As it is shown in Table II, among the DN medical cases that treated by TCM, early-stage and medium stage take the most proportion, which indicates that TCM treatment is most commonly used in the early stage and medium stage of DN. 


\section{DN TCM syndrome distribution}

Due to the complexity of DN pathogenesis, compound syndromes took a large proportion in this study. We obtained 24 standard syndromes after classifying and standardizing the compound syndromes. Table III shows the syndromes with frequency greater than or equal to 10 .

Table I Frequency of herbs used in the DN prescription

\begin{tabular}{|c|c|c|c|c|c|}
\hline Herbs & Chinese & Function & Plant source & Frequency & Ratio \\
\hline $\begin{array}{l}\text { Milkvetch root } \\
\text { (Radix Astragali seu } \\
\text { Hedysari) }\end{array}$ & 黄芪 & $\begin{array}{l}\text { (1) To stimulate the function of the spleen; (2) to } \\
\text { strengthen Qi }\end{array}$ & $\begin{array}{l}\text { Astragalus membranaceus (Fisch.) } \\
\text { Bge. var. mongholicus Bge. Hsiao.; } \\
\text { Astragalus membranaceus (Fisch.) Bge. }\end{array}$ & 209 & $76.28 \%$ \\
\hline $\begin{array}{l}\text { Indian bread } \\
\text { (Poria) }\end{array}$ & 获苓 & $\begin{array}{l}\text { (1) To invigorate the spleen function; (2) to cause } \\
\text { diuresis }\end{array}$ & Poria cocos (Schw. ) Wolf & 122 & $44.53 \%$ \\
\hline $\begin{array}{l}\text { Common yam rhizome } \\
\text { (Rhizoma Dioscoreae) }\end{array}$ & 山药 & $\begin{array}{l}\text { (1) To benefit the stomach and spleen; (2)to facilitate } \\
\text { fluid secretion; (3)to strengthen the kidney. }\end{array}$ & Dioscorea opposite Thunb. & 119 & $43.43 \%$ \\
\hline $\begin{array}{l}\text { Danshen root } \\
\text { (Radix Salviae } \\
\text { Miltiorrhizae) }\end{array}$ & 丹参 & $\begin{array}{l}\text { (1)To eliminate blood stasis;(2) to stimulate the flow of } \\
\text { blood; (3)to relieve pain, and to ease the mind. }\end{array}$ & Salvia miltiorrhiza Bge. & 108 & $39.42 \%$ \\
\hline $\begin{array}{l}\text { Asiatic cornelian } \\
\text { cherry fruit } \\
\text { (Fructus Corni) }\end{array}$ & 山茱英 & $\begin{array}{l}\text { (1) To complement the liver and kidney; (2) to } \\
\text { diminish collapse. }\end{array}$ & Cornus office Sieb. et Zucc. & 104 & $37.96 \%$ \\
\hline $\begin{array}{l}\text { Unprocessed } \\
\text { rehmannia root } \\
\text { (Radix Rehmanniae } \\
\text { Recens) }\end{array}$ & 生地 & $\begin{array}{l}\text { (1)To support yin and advance the production of } \\
\text { body fluids; (2)to clear heat and cool blood. }\end{array}$ & Rehmannia gultinosa Libosch. & 88 & $32.12 \%$ \\
\hline $\begin{array}{l}\text { Chinese angelica } \\
\text { (Radix Angelicae } \\
\text { Sinensis) }\end{array}$ & 当归 & $\begin{array}{l}\text { (1) To enrich the blood and activate blood circulation; } \\
\text { (2)to regulate menstruation, (3)to lubricate bowels. }\end{array}$ & Angelica sinensis (Oliv.) Diels & 70 & $25.55 \%$ \\
\hline $\begin{array}{l}\text { Rhubarb root and } \\
\text { rhizome (Radix et } \\
\text { Rhizoma Rhei) }\end{array}$ & 大黄 & $\begin{array}{l}\text { (1) To cause catharsis and purge away heat; (2) to } \\
\text { reduce heat in the blood and counteract toxicity;(3) to } \\
\text { eliminate blood stasis and stimulate menstrual discharge. }\end{array}$ & $\begin{array}{l}\text { Rheum palmatum L.;Rheum officinale } \\
\text { Baill.;Rheum tanguticum Maxim. ex } \\
\text { Balf. }\end{array}$ & 69 & $25.18 \%$ \\
\hline $\begin{array}{l}\text { Oriental water plantain } \\
\text { rhizome } \\
\text { (Rhizoma Alismatis) }\end{array}$ & 泽泻 & $\begin{array}{l}\text { (1)To influence dieresis; (2)to eliminate damp-heat; } \\
\text { (3)to transform dampness and to stimulate water } \\
\text { metabolism. }\end{array}$ & Alisma orientalis (Sam.) Juzep. & 65 & $23.72 \%$ \\
\hline $\begin{array}{l}\text { Largehead atractylodes } \\
\text { rhizome (Rhizoma } \\
\text { Atractylodis } \\
\text { Macrocephalae) }\end{array}$ & 白术 & $\begin{array}{l}\text { (1) To strengthen the function of the spleen and } \\
\text { benefit Qi; (2)to remove damp; (3)to strengthen } \\
\text { diuretic function. }\end{array}$ & Atractylodes macrocephala Roidz. & 62 & $22.63 \%$ \\
\hline $\begin{array}{l}\text { Sichuan lovage } \\
\text { rhizome(Rhizoma } \\
\text { Ligustici Chuanxiong) }\end{array}$ & 川芦 & $\begin{array}{l}\text { (1)To invigorate blood and to promote Qi circulation; } \\
\text { (2) to expel wind and reduce pain }\end{array}$ & Ligusticum chuanxiong Hort. & 61 & $22.26 \%$ \\
\hline $\begin{array}{l}\text { Prepared Rehmannia } \\
\text { root } \\
\text { (Radix Rehmanniae } \\
\text { Preparata) }\end{array}$ & 熟地 & $\begin{array}{l}\text { (1)To nourish Yin and replenish blood; (2) to promote } \\
\text { the essence of life and marrow. }\end{array}$ & Rehmannia gultinosa Libosch. & 55 & $20.07 \%$ \\
\hline $\begin{array}{l}\text { Tangshen(Radix } \\
\text { Codonopsis) }\end{array}$ & 党参 & $\begin{array}{l}\text { (1) To promote Qi; (2) to advance the function of the } \\
\text { spleen. }\end{array}$ & $\begin{array}{l}\text { Codonopsis pilosula (Franch.) Nannf.; } \\
\text { Codonopsis pilosula Nannf. var. } \\
\text { modesta (Nannf.) L. T. Shen; } \\
\text { Codonopsis tangshen Oliv. }\end{array}$ & 48 & $17.52 \%$ \\
\hline $\begin{array}{l}\text { Tree peony root bark } \\
\text { (Cortex Moutan Radicis) }\end{array}$ & 丹皮 & $\begin{array}{l}\text { (1) To clear heat from blood; (2) to activate blood } \\
\text { circulation and to remove blood stasis. }\end{array}$ & Paeonia suffruticosa Andr. & 48 & $17.52 \%$ \\
\hline $\begin{array}{l}\text { Heterophylly } \\
\text { falsestarwort root } \\
\text { (Radix Pseudostellariae) }\end{array}$ & 太子参 & $\begin{array}{l}\text { (1) To benefit Qi and active the spleen function; (2) to } \\
\text { reinforce fluid secretion. }\end{array}$ & $\begin{array}{l}\text { Pseudostellaria heterophylla (Miq.) } \\
\text { Pax ex Pax et Hoffm. }\end{array}$ & 42 & $15.33 \%$ \\
\hline
\end{tabular}




\begin{tabular}{|c|c|c|c|c|c|}
\hline Herbs & Chinese & Function & Plant source & Frequency & Ratio \\
\hline $\begin{array}{l}\text { Dodder seed } \\
\text { (Semen Cuscutae) }\end{array}$ & 菟丝子 & $\begin{array}{l}\text { (1)To arrest abnormal urination; (2)to prevent abortion, } \\
\text { (3)to improve eyesight and relieve diarrhea by supplying } \\
\text { and reinforcing the function of the liver and kidney. }\end{array}$ & $\begin{array}{l}\text { Cuscuta chinensis Lam.;Cuscuta } \\
\text { japonica Choisy }\end{array}$ & 42 & $15.33 \%$ \\
\hline $\begin{array}{l}\text { Leech } \\
\text { (Hirudo) }\end{array}$ & 水蛭 & To remove blood stasis & $\begin{array}{l}\text { Whitmania pigra Whitman.;Hirudo } \\
\text { nipponica Whitman.;Whitmania } \\
\text { acranulata Whitman. }\end{array}$ & 42 & $15.33 \%$ \\
\hline $\begin{array}{l}\text { Gordon euryale seed } \\
\text { (Semen Euryales) }\end{array}$ & 苂实 & $\begin{array}{l}\text { (1)To reinforce the kidney to retain the essence of life; } \\
\text { (2)to remove dampness and to strengthen the spleen; } \\
\text { (3)to alleviate loose bowels. }\end{array}$ & Euryale ferox Salisb. & 39 & $14.23 \%$ \\
\hline $\begin{array}{l}\text { Cherokee rose fruit } \\
\text { (Fructus Rosae } \\
\text { Laevigatae) }\end{array}$ & 金桜子 & $\begin{array}{l}\text { (1)To keep the essence of life; (2)to advance the } \\
\text { function of kidney; (3)to stop diarrhea, to control } \\
\text { urination. }\end{array}$ & Rosa laevigata Michx. & 39 & $14.23 \%$ \\
\hline $\begin{array}{l}\text { Peony root (Radix } \\
\text { Paeoniae Rubra) }\end{array}$ & 赤苻 & $\begin{array}{l}\text { (1)To remove heat from blood; (2)to remove blood } \\
\text { stasis; (3)to relieve pain. }\end{array}$ & $\begin{array}{l}\text { Paeonia lactiflora pall.;Paeonia } \\
\text { veitchii Lynch }\end{array}$ & 38 & $13.87 \%$ \\
\hline $\begin{array}{l}\text { Barbary wolfberry fruit } \\
\text { (Fructus Lycii) }\end{array}$ & 枸杞 & $\begin{array}{l}\text { (1)To reinforce the kidney and liver and to supply the } \\
\text { essence of life;(2) to benefit eyesight. }\end{array}$ & Lycium barbarum L. & 37 & $13.50 \%$ \\
\hline $\begin{array}{l}\text { Liquorice root } \\
\text { (Radix Glycyrrhizae) }\end{array}$ & 甘草 & $\begin{array}{l}\text { (1)To advance the function of the spleen and advance } \\
\text { Qi; (2)to dispel phlegm; (3)to alleviate spasmodic } \\
\text { pain; (4)to moderate herbs and to decrease toxicity. }\end{array}$ & $\begin{array}{l}\text { Glycyrrhiza uralensis Fisch; } \\
\text { Glycyrrhiza inflate Bat.;Glycyrrhiza } \\
\text { glabra L. }\end{array}$ & 36 & $13.14 \%$ \\
\hline $\begin{array}{l}\text { Safflower } \\
\text { (Flos Carthami) }\end{array}$ & 红花 & $\begin{array}{l}\text { (1)To stimulate blood circulation;(2) to eliminate } \\
\text { blood stasis; (3)to relieve pain. }\end{array}$ & Carthamus tinctorius $\mathrm{L}$. & 35 & $12.77 \%$ \\
\hline $\begin{array}{l}\text { Dwarf lilyturf tuber } \\
\text { (Radix Ophiopogonis) }\end{array}$ & 麦冬 & $\begin{array}{l}\text { (1)To nourish Yin and advance the production of } \\
\text { body fluid;(2)to benefit the lung; (3)to ease the mind. }\end{array}$ & $\begin{array}{l}\text { Ophiopogon japonicus ( Thunb. } \\
\text { Ker-Gawl.) }\end{array}$ & 33 & $12.04 \%$ \\
\hline $\begin{array}{l}\text { Kudzuvine root } \\
\text { (Radix Puerariae) }\end{array}$ & 葛根 & $\begin{array}{l}\text { (1)To relieve fever; (2) to stimulate the production of } \\
\text { body fluid;(3)to relief diarrhea. }\end{array}$ & $\begin{array}{l}\text { Pueraria lobata (Willd.) } \\
\text { Ohwi;Pueraria thomsonii Benth. }\end{array}$ & 32 & $11.68 \%$ \\
\hline $\begin{array}{l}\text { Motherwort herb } \\
\text { (Herba Leonuri) }\end{array}$ & 益母草 & $\begin{array}{l}\text { (1)To stimulate blood circulation and to eliminate } \\
\text { blood stasis; (2)to stimulate diuresis and relieve } \\
\text { edema; (3)to lower blood pressure. }\end{array}$ & Leonurus heterophyllus Sweet & 32 & $11.68 \%$ \\
\hline $\begin{array}{l}\text { Peach seed } \\
\text { (Semen Persicae) }\end{array}$ & 桃仁 & $\begin{array}{l}\text { (1)To stimulate blood circulation; (2)to remove } \\
\text { phlegm; (3)to smooth the bowels. }\end{array}$ & $\begin{array}{l}\text { Prunus persica (L.) Batch.;Prunus } \\
\text { davidiana (Carr.) Franch. }\end{array}$ & 31 & $11.31 \%$ \\
\hline $\begin{array}{l}\text { Earthworm } \\
\text { (Lumbricus) }\end{array}$ & 地龙 & $\begin{array}{l}\text { (1)To remove heat;(2)to remove obstruction from the } \\
\text { collaterals; (3)to advance dieresis and to relieve } \\
\text { asthma; (4) to remove blood stasis. }\end{array}$ & $\begin{array}{l}\text { Phereti a aspergillu (E. Perrier); } \\
\text { Pheretima vulgaris Chen; } \\
\text { Pheretimaguillelmi(Michaelsen); } \\
\text { Phereti apectinifera Michaelsen }\end{array}$ & 30 & $10.95 \%$ \\
\hline $\begin{array}{l}\text { Figwort root } \\
\text { (Radix Scrophulariae) }\end{array}$ & 玄参 & $\begin{array}{l}\text { (1)To remove heat from blood;(2)to advance Yin; (3)to } \\
\text { decrease toxicity. }\end{array}$ & Scrophularia ningpoensiis Hemsl. & 28 & $10.22 \%$ \\
\hline $\begin{array}{l}\text { Twotoothed } \\
\text { achyranthes root } \\
\text { (Radix Achyranthis } \\
\text { Bidentatae) }\end{array}$ & 怀牛膝 & $\begin{array}{l}\text { (1)To supply the liver and the kidney; (2)to strengthen } \\
\text { the bones;(3)to remove blood stasis; (4)to lead the } \\
\text { blood to flow downward. }\end{array}$ & Achyranthes bidentata $\mathrm{Bl}$ & 28 & $10.22 \%$ \\
\hline $\begin{array}{l}\text { Solomonseal rhizome } \\
\text { (Rhizoma Polygonati) }\end{array}$ & 黄精 & $\begin{array}{l}\text { (1)To benefitQi and Yin;(2)to advance the function of } \\
\text { the spleen; (3)to benefit the kidney. }\end{array}$ & $\begin{array}{l}\text { Polygonatum kingianum Coll. et } \\
\text { Hemsl.; Polygonatum sibiricum } \\
\text { Red.;Polygonatum cyrtonema Hua }\end{array}$ & 28 & $10.22 \%$ \\
\hline $\begin{array}{l}\text { Epimedium herb } \\
\text { (Herba Epimedii) }\end{array}$ & 仙灵脾 & $\begin{array}{l}\text { (1)To promote the Yang of the kidney; (2)to advance } \\
\text { the tendons and bones; (3)to relieve rheumatic disease. }\end{array}$ & $\begin{array}{l}\text { Epimediumbrevicornum Maxim.; } \\
\text { Epimedium sagittatum (Sieb. et Zucc.) } \\
\text { Maxim.;Epimedium pubescens } \\
\text { Maxm.;Epimedium wushanense T. S. } \\
\text { Ying;Epimedium koreanum Nakai }\end{array}$ & 27 & $9.85 \%$ \\
\hline
\end{tabular}


Continued

\begin{tabular}{|c|c|c|c|c|c|}
\hline Herbs & Chinese & Function & Plant source & Frequency & Ratio \\
\hline $\begin{array}{l}\text { Golden thread } \\
\text { (Rhizoma Coptidis) }\end{array}$ & 黄连 & $\begin{array}{l}\text { (1)To eliminate damp-heat and to reduce the fire; } \\
\text { (2) to counteract toxicity. }\end{array}$ & $\begin{array}{l}\text { Coptis Chinensis Franch.; Coptis } \\
\text { deltoidea C. Y. Cheng et Hsiao.;Coptis } \\
\text { teeta Wall. }\end{array}$ & 26 & $9.49 \%$ \\
\hline $\begin{array}{l}\text { Sanqi } \\
\text { (Radix Notoginseng) }\end{array}$ & 三七 & $\begin{array}{l}\text { (1)To remove blood stasis; (2)to prevent bleeding and } \\
\text { to relieve pain. }\end{array}$ & $\begin{array}{l}\text { Panax notoginseng (Burk. ) F. H. } \\
\text { Chen. }\end{array}$ & 26 & $9.49 \%$ \\
\hline $\begin{array}{l}\text { Glossy privet fruit } \\
\text { (Fructus Ligustri } \\
\text { Lucidi) }\end{array}$ & 女贞子 & $\begin{array}{l}\text { (1)To advance the function of the liver and } \\
\text { kidney; (2) to benefit eyesight and to benefit the } \\
\text { growth of hair. }\end{array}$ & Ligustru lucidu Ait. & 26 & $9.49 \%$ \\
\hline $\begin{array}{l}\text { Chinese magnoliavine } \\
\text { fruit } \\
\text { (Fructus Schisandrae } \\
\text { Chinensis) }\end{array}$ & 五味子 & $\begin{array}{l}\text { (1)To arrest discharges; (2)to advance Qi and to } \\
\text { stimulate the fluid secretion; (3)to reinforce the } \\
\text { kidney. }\end{array}$ & $\begin{array}{l}\text { Schisandra chinensis (Turcz.) Baill.; } \\
\text { Schizandra sphenanthera Rehd. Et } \\
\text { Wils. }\end{array}$ & 25 & $9.12 \%$ \\
\hline $\begin{array}{l}\text { Winnged Euonymus } \\
\text { Twig (Ramulus } \\
\text { Euonymi) }\end{array}$ & 鬼箭羽 & $\begin{array}{l}\text { (1)To activate blood and to remove blood stasis; (2)to } \\
\text { relief pain }\end{array}$ & Euonymus alatus(Thunb.) Sieb & 25 & $9.12 \%$ \\
\hline $\begin{array}{l}\text { Prepared common } \\
\text { monkshood branched } \\
\text { root }(\text { Radix Aconiti } \\
\text { Lateralis Preparata })\end{array}$ & 附子 & $\begin{array}{l}\text { (1)To promote Yang and to advance the function of } \\
\text { kidney; (2) to cause restoration from collapse; (3) to } \\
\text { dispel wind, cold and damp. }\end{array}$ & Aconitum carmichaeli Debx. & 24 & $8.76 \%$ \\
\hline $\begin{array}{l}\text { Debark peony root } \\
\text { (Radix Paeoniae Alba) }\end{array}$ & 白䓎 & $\begin{array}{l}\text { (1) To soothe liver Yang; (2)to supply blood and } \\
\text { nourish the Yin; (3)to relief pain. }\end{array}$ & Paeonia lactiflora pall. & 20 & $7.30 \%$ \\
\hline
\end{tabular}

Table II Frequency of DN stage

\begin{tabular}{ccc}
\hline DN Stage & Frequency & Ratio \\
\hline Early-stage & 147 & $53.65 \%$ \\
Medium stage & 96 & $35.04 \%$ \\
End-stage & 31 & $11.31 \%$ \\
\hline
\end{tabular}

Table III Frequency of DN syndrome

\begin{tabular}{ccc}
\hline Syndrome & Frequency & Ratio \\
\hline Deficiency Qi and Yin & 112 & $40.88 \%$ \\
Obstruction of collaterals by blood stasis & 78 & $28.47 \%$ \\
Deficiency of liver and kidney & 62 & $22.63 \%$ \\
Damp-heat stasis obstruction & 48 & $17.52 \%$ \\
Yin asthenia generating intrinsic heat & 42 & $15.33 \%$ \\
Phlegm and blood stasis & 35 & $12.77 \%$ \\
Deficiency of yin and dampness-heat & 30 & $10.95 \%$ \\
The mutual knot of damp heat and phlegm and stasis & 27 & $9.85 \%$ \\
Hyperactivity of fire due to deficiency of kidney & 24 & $8.76 \%$ \\
Asthenia of both the spleen and kidney & 19 & $6.93 \%$ \\
The weakness of the spleen and the stomach & 17 & $6.20 \%$ \\
Qi stagnation and blood stasis & 14 & $5.11 \%$ \\
Deficiency of spleen-yang and kidney-yang & 12 & $4.38 \%$ \\
Wind formation from blood dryness & 11 & $4.01 \%$ \\
\hline
\end{tabular}

As it is shown in Table III and Figure 1, the most common syndromes of DN are deficiency Qi and Yin, obstruction of collaterals by blood stasis, deficiency of liver and kidney, damp-heat stasis obstruction, Yin asthenia generating intrinsic heat, and Phlegm and blood stasis.

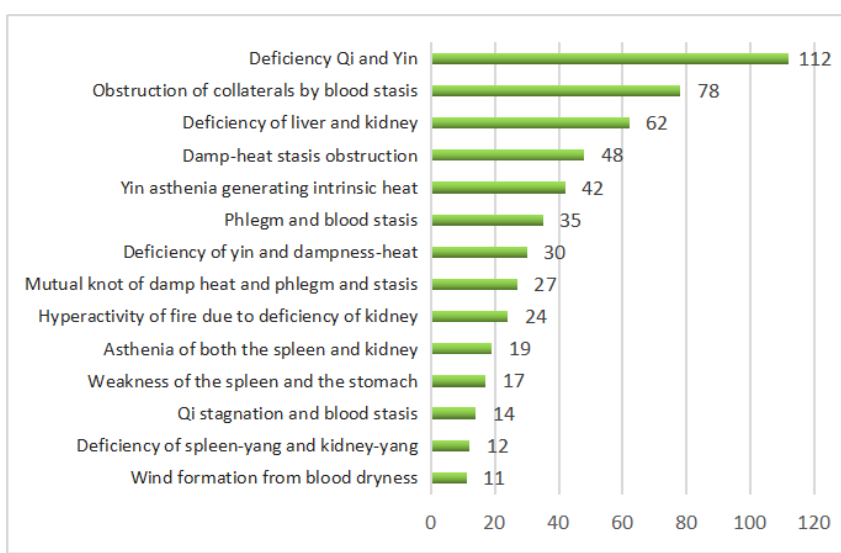

Figure 1 frequency of DN syndrome

\section{Frequency of syndrome pathological element}

The concept of syndrome element was put forward by Professor Zhu Wenfeng ${ }^{17,18}$, which had an important influence on TCM academic development. The syndrome element is the smallest unit of TCM syndromes. As it is shown in Table IV and Figure 2, the most frequently common syndrome elements of DN are Yin deficiency, blood stasis, Qi deficiency, endogenous heat and phlegm.

\subsection{Association rules analysis}

To explore the association rules among herbs used in DN, we 
Table IV Frequency of syndrome elements

\begin{tabular}{ccc}
\hline Syndrome elements & Frequency & Ratio \\
\hline Yin deficiency & 194 & $70.80 \%$ \\
Blood stasis & 168 & $61.31 \%$ \\
Qi deficiency & 159 & $58.03 \%$ \\
Endogenous heat & 142 & $51.82 \%$ \\
Phlegm & 126 & $45.99 \%$ \\
Turbid bane; & 75 & $27.37 \%$ \\
Kidney deficiency & 85 & $31.02 \%$ \\
Yang deficiency & 62 & $22.63 \%$ \\
Blood deficiency & 49 & $17.88 \%$ \\
Dryness & 38 & $13.87 \%$ \\
\hline
\end{tabular}

perform association analysis by the Apriori algorithm. The association rule was ranked by confidence. Confidence stands for the percentage of rule support to antecedent support; while support stands for the probability of the antecedent and consequent appearing at the same time. Only confidence greater than $85 \%$ and support greater than 15\% were displayed in Table V. In Figure 3, the thickness of the line represents the degree of association, the thicker the line, the higher the degree of association.

\subsection{Cluster analysis}

To explore the herbal medication rules in TCM treatment of DN, we perform cluster analysis on herbs with frequency more than or equal to 30 were analyzed by cluster analysis. Basic information about the core herbs obtained from the results of cluster analysis is presented in Figure 4 and Figure 5.

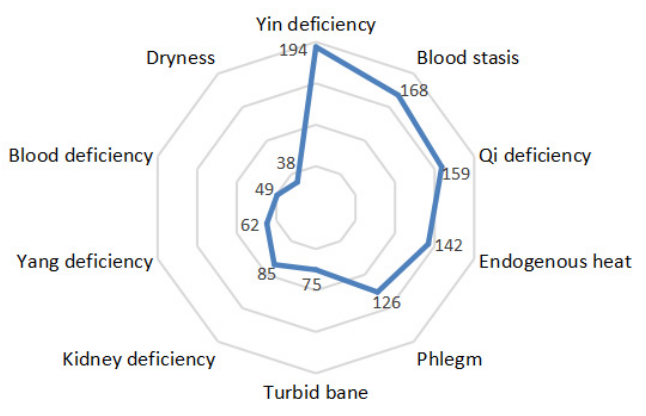

Figure 2 Frequency of syndrome elements

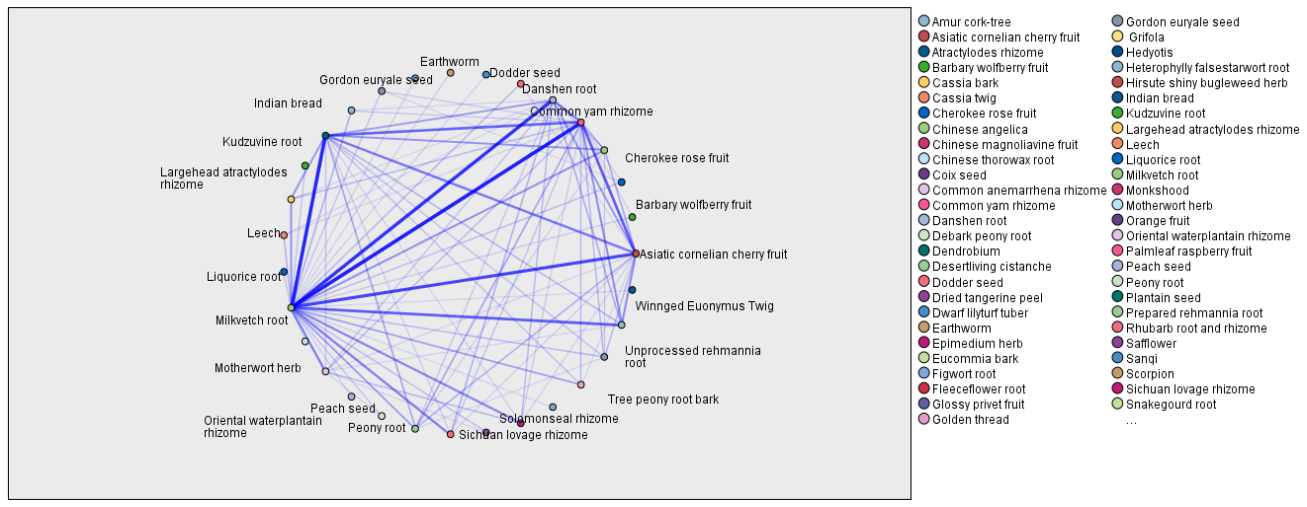

Figure 3 Association results of herbs used in DN

Table V Herb association rules

\begin{tabular}{|c|c|c|c|}
\hline Consequent & Antecedent & Support \% & Confidence \% \\
\hline Milkvetch root $=\mathrm{T}$ & Asiatic cornelian cherry fruit $=\mathrm{T}$ and Danshen root $=\mathrm{T}$ & 18.02 & 95.92 \\
\hline Milkvetch root $=\mathrm{T}$ & Danshen root $=\mathrm{T}$ and Indian bread $=\mathrm{T}$ & 17.28 & 95.75 \\
\hline Milkvetch root $=\mathrm{T}$ & Danshen root $=\mathrm{T}$ and Common yam rhizome $=\mathrm{T}$ & 23.53 & 95.31 \\
\hline Milkvetch root $=\mathrm{T}$ & Asiatic cornelian cherry fruit $=\mathrm{T}$ and Danshen root $=\mathrm{T}$ and Common yam rhizome $=\mathrm{T}$ & 15.07 & 95.12 \\
\hline Milkvetch root $=\mathrm{T}$ & Sichuan lovage rhizome $=\mathrm{T}$ & 22.43 & 95.08 \\
\hline Milkvetch root $=\mathrm{T}$ & Tangshen $=\mathrm{T}$ & 17.65 & 93.75 \\
\hline Milkvetch root $=\mathrm{T}$ & Danshen root $=\mathrm{T}$ & 39.71 & 89.81 \\
\hline Milkvetch root $=\mathrm{T}$ & Asiatic cornelian cherry fruit $=\mathrm{T}$ and Common yam rhizome $=\mathrm{T}$ & 27.94 & 89.47 \\
\hline Milkvetch root $=\mathrm{T}$ & Indian bread $=\mathrm{T}$ and Common yam rhizome $=\mathrm{T}$ & 26.84 & 89.04 \\
\hline Milkvetch root $=\mathrm{T}$ & Rhubarb root and rhizome $=\mathrm{T}$ & 25.37 & 88.41 \\
\hline Milkvetch root $=\mathrm{T}$ & Common yam rhizome $=\mathrm{T}$ & 43.75 & 88.24 \\
\hline Milkvetch root $=\mathrm{T}$ & Asiatic cornelian cherry fruit $=\mathrm{T}$ and Indian bread $=\mathrm{T}$ and Common yam rhizome $=\mathrm{T}$ & 18.75 & 88.24 \\
\hline Milkvetch root $=\mathrm{T}$ & Chinese angelica $=\mathrm{T}$ & 25.74 & 87.14 \\
\hline Common yam rhizome $=\mathrm{T}$ & Asiatic cornelian cherry fruit $=\mathrm{T}$ and Indian bread $=\mathrm{T}$ and Milkvetch root $=\mathrm{T}$ & 19.12 & 86.54 \\
\hline Milkvetch root $=\mathrm{T}$ & Unprocessed rehmannia root $=\mathrm{T}$ & 32.35 & 86.36 \\
\hline Common yam rhizome $=\mathrm{T}$ & Oriental waterplantain rhizome $=\mathrm{T}$ and Asiatic cornelian cherry fruit $=\mathrm{T}$ & 15.44 & 85.71 \\
\hline Asiatic cornelian cherry fruit $=\mathrm{T}$ & Oriental waterplantain rhizome $=\mathrm{T}$ and Common yam rhizome $=\mathrm{T}$ & 15.44 & 85.71 \\
\hline Indian bread $=\mathrm{T}$ & Oriental waterplantain rhizome $=\mathrm{T}$ and Common yam rhizome $=\mathrm{T}$ & 15.44 & 85.71 \\
\hline Milkvetch root $=\mathrm{T}$ & Asiatic cornelian cherry fruit $=\mathrm{T}$ & 38.24 & 85.62 \\
\hline Common yam rhizome $=\mathrm{T}$ & Prepared rehmannia root $=\mathrm{T}$ & 44.85 & 85.43 \\
\hline
\end{tabular}




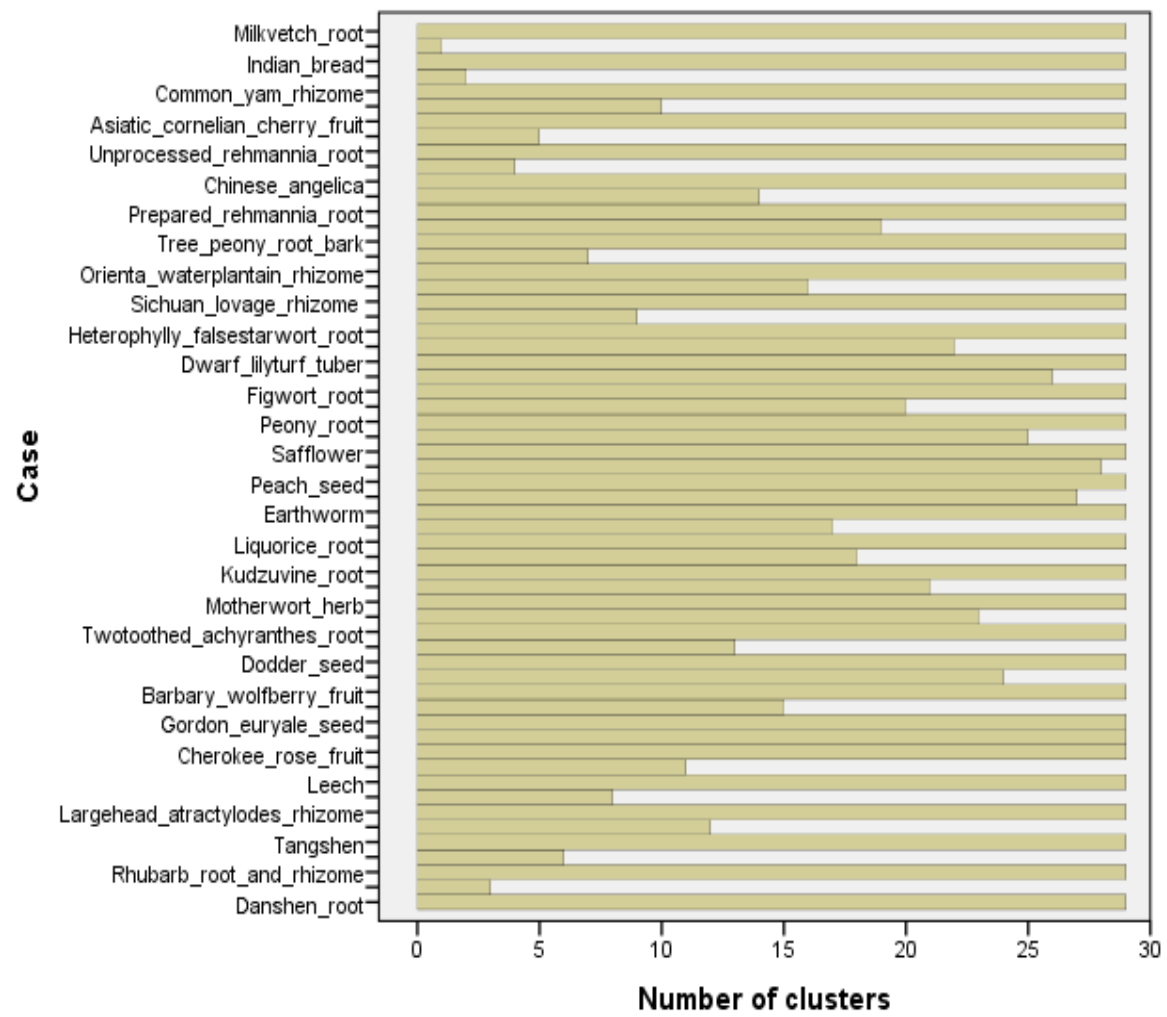

Figure 4 Icicle chart of herbs (with frequency more than or equal to 30) used in DN

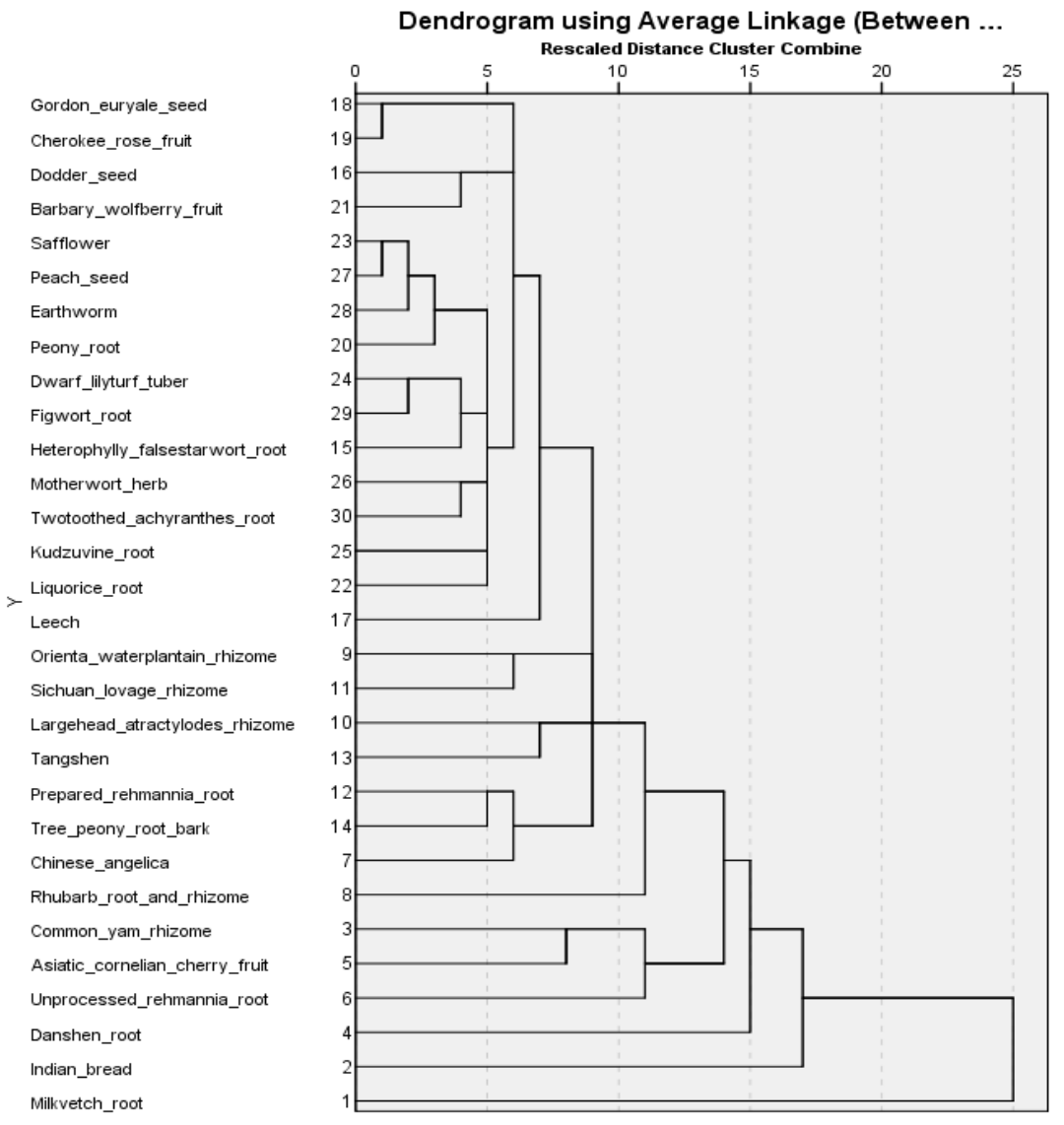

Figure 5 Dendrogram of herbs (with frequency more than or equal to 30) used in DN 
By clustering, 12 sets of core couplet medicines were obtained: 1 . Unprocessed Rehmannia root \& Asiatic cornelian cherry fruit \& common yam rhizome; 2. Tree peony root bark \& prepared Rehmannia root; 3. Chinese angelica\& tree peony root bark \& prepared Rehmannia root; 4 . Tangshen \& largehead atractylodes rhizome; 5. Sichuan lovage rhizome \& oriental water plantain rhizome; 6.Twotoothed achyranthes root \& motherwort herb; 7. Heterophylly falsestarwort root\& figwort root\& dwarf lilyturf tuber; 8. Figwort root\& dwarf lilyturf tuber; 9. Peach seed \& safflower; 10. Peony root \& earthworm \&peach seed \& safflower; 11. Barbary wolfberry fruit \& dodder seed; 12. Cherokee rose fruit \&GordonEuryale seed.

\section{DISCUSSION}

Overall, in our study, by analyzing 274 prescriptions used in TCM for $\mathrm{DN}$ in the recent 20 years, we found that $\mathrm{DN}$ is quite complicated and is a combination of deficiency and excess in the TCM perspective, which is consistent with other views from ancient times to the present. The results of the paper suggest that the use of herbs is steady with the DN pathogenesis. Syndrome differentiation, proposed by the TCM Saint Zhang Zhongjing (circa 150-154 A.D. to 215-219 A.D.), is the basis in TCM treatment, which means personalized treatment based on different patients and different TCM syndrome. ${ }^{19}$ Therefore, the study of syndromes plays a key role in the TCM treatment of $\mathrm{DN} .^{20}$ According to the guidelines for prevention and TCM treatment of DN proposed by the Chinese Medicine Association, the pathogenesis of diabetic nephropathy is based on the deficiency of Qi and Yin. So tonify Qi and Yin go throughout the treatment ${ }^{6}$. Our study supports this view. In our study, the five most common syndromes of DN are Yin deficiency, blood stasis, Qi deficiency, endogenous heat and phlegm. Within them, the frequency of deficiency Qi and Yin is 112, and the ratio is $40.88 \%$, accounting for the highest proportion. The frequency of obstruction of collaterals by blood stasis was 78 , and the percentage was $28.47 \%$. The frequency of deficiency of liver and kidney was 62, and the ratio was $22.63 \%$. Clearly, these three syndromes accounted for the largest proportion. In addition, the frequency of damp-heat stasis obstruction was 48 , and the ratio was $17.52 \%$. The frequency of Yin asthenia generating intrinsic heat was 42 , and the percentage was $15.33 \%$. To be more specific, we further explored the pathological elements of $\mathrm{DN}$, which shows that the five most general pathological elements are Yin deficiency $(70.80 \%)$, blood stasis (61.31\%), Qi deficiency (58.03\%), endogenous heat $(51.82 \%)$ and phlegm (45.99\%).

Although there is a common consensus that the basis of Qi and Yin deficiency is the basis of DN, due to the complex and compound syndrome differentiation system in TCM, debates on the syndrome of DN never stop. ${ }^{21-24}$ This study shows that the basic pathogenesis of DN is the deficiency of Qi and Yin, while blood stasis runs through the whole course of DN based on the saying, "long-term chronic diseases transforming to collaterals." As it is fully understood that the syndrome of $\mathrm{DN}$ is not fixed but a dynamic development progress. ${ }^{25}$ In TCM perspective, in the early stage of the disease, the lung, stomach, lung and kidney suffer from the loss of Yin fluid. Throughout time, the Yin deficiency affects Qi and Yang, causing Qi and Yin deficiency, Yin and Yang deficiency, and spleen and kidney Yang deficiency. ${ }^{20}$ Throughout the disease, intermingled deficiency and excess occur, such as Qi and Yin deficiency with fewer blood veins astringent, Qi and blood deficiency with cold stagnation and blood stasis, etc., while dampness and blood stasis are the important factors cannot be ignored. With the progression of DN, the clinical manifestations of water dampness and blood stasis are gradually aggravated. Water dampness repression and stagnation of blood stasis are not only related to the activity of the disease, but also an important factor leading to aggravating the impairment of renal function. ${ }^{24}$

In addition to syndromes, herbs are important carriers of TCM. As we know, inflammation and oxidative stress are two closely linked DN processes. ${ }^{26-28}$ Current research shows that lots of herbs have been proven to have anti-inflammatory and antioxidative effects, such as Milkvetch root, ${ }^{29}$ Danshen root, ${ }^{30}$ and Largehead atractylodes rhizome, ${ }^{31}$ etc. In addition, renal fibrosis is the ultimate common pathway leading to the early development of chronic kidney disease progress to end-stage renal disease. Therefore, anti-fibrotic therapy is an effective treatment for DN. A lot of herbs such as Chinese angelica, Mlkvetch root, Rhubarb root and rhizome, are proven to have antifibrotic effect and immunomodulation effects as well. ${ }^{32-35}$ To investigate the most frequently used herbs in DN, we rank the herbs in terms of the frequency. Our analysis results suggest that herbs with number of times greater than 30 are as follows: milkvetch root, Indian bread, common yam rhizome, danshen root, Asiatic cornelian cherry fruit, unprocessed Rehmannia root, Chinese angelica, rhubarb root and rhizome, oriental water plantain rhizome, largehead atractylodes rhizome, Sichuan lovage rhizome, prepared Rehmannia root,Tangshen, tree peony root bark, heterophylly falsestarwort root, dodder seed, leech, gordon euryale seed, cherokee rose fruit, peony root, barbary wolfberry fruit, liquorice root, safflower, dwarf lilyturf tuber, kudzuvine root, motherwort herb and peach seed. The frequency of Milkvetch root is 209 and $76.28 \%$ of prescriptions collected contain it.

Milkvetch root is used to fortify Qi, the vital energy of life. It promotes the protective Qi and solidifies the external of the body as well. In TCM theory, it is sweet and slightly warm in nature. It belongs to the meridian of the spleen and lungs. It is reported to (1)raise the sum of polymorphoctyes and eukocytes in peripheral blood and strengthening the lymphocyte-blastogenesis; (2)cardiotonic; (3)dilate coronary artery and capillaries..$^{29}$ Danshen root, Chinese angelica, rhubarb root and rhizome, Sichuan lovage rhizome, leech and safflower can stimulate blood circulation and eliminate blood stasis. Danshen root can dispel the blood stasis and relief pain, stimulate the blood and remove heat. It is reported that (1)the tanshinone can be used as a broad-spectrum bactericide, can stimulate the coronary flow, and expand coronary artery; (2)influence many blood clotting factors, control the aggregation of platelet and improve the level of cAMP in thrombocytes..$^{30}$ Chinese angelica can improve the blood, relief pain and stimulate blood circulation. It is reported to (1) diminish myocardial ischemiaactuated by pituitary; (2) expand coronary artery, reduce oxygen consumption and improve coronary flow. ${ }^{36}$ Rhubarb is usually used to decrease heat and moves the bowels, clears heat from the blood, dispels stasis and unblocks the Channels. It can strongly dispel blood stasis and reduces immobile masses. It is reported to (1) Emodin carry out bacteriostatic influence through restraining the synthesis of RNA, DNA and protein in bacteria; (2) Emodin plays role as a laxative, a tyrosine kinase inhibitor, an antineoplastic agent, and a plant metabolite; (3) facilitate the biliary secretion and promote the sum of bile acid and bilirubin. ${ }^{37}$ Safflower promotes the blood, disperses stasis, relief pain, and unblocks the Channels. It is reported to (1) improve the coronary 
flow; (2) stimulates uteri and intestines in vitro; (3) lower blood pressure. $^{38}$ Tree peony root bark can activate blood circulation, clear pathogenic heat from the blood, and remove blood stasis. It is reported to (1) antibacterial and anti-inflammatory; (2) analgesic. ${ }^{39}$ Unprocessed Rehmannia root can be used to cool blood, remove heat, nourish yin, and stimulate the production of fluids. It is reported to lower the blood sugar level. ${ }^{40}$ Heterophylly falsestarwort root can strengthen Qi, advance the spleen function, and stimulate fluid secretion. ${ }^{41}$ Indian bread and largehead atractylodes rhizome can clear damp, promote dieresis, strengthen the spleen and reduce phlegm. Indian bread is commonly used to (1) treat edema with oliguria; (2)diminished function of the spleen, which is marked by anorexia dizziness; (3) palpitation result in retained fluid. ${ }^{42}$ Largehead atractylodes rhizome is usually used to eliminate damp by causing dieresis, to promote the spleen, to replenish qi, and is proven to promote phagocytosis and the function of adrenal cortex ${ }^{43}$. Common yam rhizome advances the function of the spleen and stomach, promotes the function of the kidneys, and generates fluids. It is proven to promote the phagocytosis of leukocyte in vitro. ${ }^{44}$ To conclude, herbs for tonifying Qi, nourishing Yin, stimulating blood circulation to remove blood stasis, nourishing liver and kidney, removing phlegm take account for alarge proportion among the high-frequency medicinal to treat $\mathrm{DN}$.

In addition, the accumulated experiences in the practice of TCM indicate that the combination of herbs is more effective than herb used in isolation. So we not only emphasize the isolated herbs but also the combined herbs in prescriptions. In accordance with the data mining analyses result, 13 sets of commonly-used combined herbs are listed and discussed here.

1) Rehmannia root \& Usiatic cornelian cherry fruit \& Common yam rhizome. Rehmannia root, usiatic cornelian cherry fruit and common yam rhizome are combined herbs in Liuwei Dihuang Wan, which are commonly used to enrich the kidneys Yin. Rehmannia root can remove heat and cool the blood, enhance Yin and generates fluids; usiatic cornelian cherry fruit can benefit the liver and kidneys, and secures conditions from collapsing; common yam rhizome nourishes the spleen and stomach, generates fluids, advances the function of the kidneys and retains Jing.

2) Chinese angelica\&Tree peony root bark \& prepared Rehmannia root. Chinese angelica is sweet, acrid and warm in nature, and it belongs to Channel of liver, heart and spleen. Chinese angelica nourishes and invigorates the blood, regulates menses and relieves pain, and moistens the intestines and moves the bowels. As is mentioned above, tree peony root bark and prepared Rehmannia root can both tonify Yin and kidney, and clear heat and invigorate the blood. With Chinese angelica, this herb combination can nourish and the blood, tonify Yin and kidney, and clear heat and invigorate the blood.

3) Peony root \& earthworm \& Peach seed \& safflower. This combination is commonly used to invigorate the blood. Tree peony root barkclears heat and cools the blood and invigorates the blood and dispels the blood stasis. Clears heat and settles fright, unblocks the collaterals, calms wheezing and promotes urination. Peach seed invigorates the blood and dispels blood stasis, and moistens the intestines and moves the bowels. Safflower invigorates the blood and unblocks the channels and disperses stasis and alleviates pain.

4) Barbary wolfberry fruit \& dodder seed. Barbary wolfberry fruit nourishes and tonifies the liver and kidneys and benefits Jing and improves vision. Dodder seed tonifies the liver and kidneys and secures Jing and reserves urine.The compatibility of barbary wolfberry fruit and dodder seed can increase strength of tonifying the liver and kidneys and securing Jing and reserving urine.

5) Cherokee rose fruit \&Gordon Euryale seed. Cherokee rose fruitsecures Jing and contains urination and binds up the intestines and stops diarrhea. Gordon Euryale seed strengthens the spleen and stops diarrhea, stabilizes the kidneys and astringes Jing, expels dampness and stops the discharge. The compatibility of Cherokee rose fruit and Gordon euryale seed strengthens the spleen and kidney, and expels dampness and stops discharge.

6) Tree peony root bark \& prepared Rehmannia root. Tree peony root bark influences heart, liver and kidney, and can clears heat and cools the blood and invigorates the blood and dispels the blood stasis. Prepared Rehmannia root influences liver, kidney, and can tonify Yin and nourish the blood and tonify Jing and supplement bone marrow. This herb combination can both tonify Yin and kidney, and clear heat and invigorate the blood.

7) Sichuan lovage rhizome \& oriental water plant in rhizome. Oriental water plantain rhizome is sweet and cold in nature, and it belongs to the channel of kidneys and bladder. Oriental water plantain rhizome promotes urination and drains dampheat.Sichuan lovage rhizome invigorates the blood and moves Qi and expels wind and alleviates pain. The compatibility of oriental water plantain rhizome and Sichuan lovage rhizome can both promote blood and Qi circulation, and drain damp-heat.

8) Milkvetch root \& Lovage rhizome. Milkvetch root is warm and sweet in nature, and it belongs to the channel of lung and spleen. It is usually used to reinoforce Qi and invigorates the function of the spleen. Lovage rhizome is pungent and bitter in nature, and belongs to channel of bladder and liver. It can be used to relieve rheumatic conditions and to remove obstruction from the channels and relieve pain. The combined herbs can not only reinoforce Qi but also remove obstruction from the channels and relieve pain.

9) Twotoothed achyranthes root \& motherwort herb. Twotoothed achyranthes roottonifies the liver and kidneys, strengthens sinews and bones, dispel stasis and unblock the channels, induce the blood moving downward. Motherwort herb nvigorates the blood and regulates menses and promotes urination and reduces swelling. The compatibility of two toothed achyranthes root and motherwort herb can both tonify the liver and kidneys and nvigorate the blood.

10) Heterophylly falsestarwort root\&Figwort root\& dwarf lilyturf tuber. Heterophylly falsestarwort roottonifies Qi and strengthens the spleen, and generates fluids and moistens the lungs. Figwort rootcools the blood and nourishes Yin, and purges fire and resolves toxicity. Dwarf lilyturf tuber nourishes Yin and moistens lungs, and clears heart and calms the spirit.The compatibility is a common combination to nourish Yin, clear heart and notify Qi and strengthens the spleen.

11) Figwort root \& dwarf lilyturf tuber. Figwort rootcools the blood and nourishes Yin, and purges fire and resolves toxicity. Dwarf lilyturf tuber nourishes Yin and moistens the lungs, and clears heart and calms the spirit.The compatibility of figwort root and dwarf lilyturf tuber is a common combination to nourish Yin and clear heart.

12) Peach seed \& safflower. Peach seed invigorates the blood and dispels blood stasis, and moistens the intestines and moves the bowels. Safflower invigorates the blood and unblocks the channels and disperses stasis and alleviates pain. Two herbs used together can promote each other, and increase the strength of promoting 
blood circulation, removing new blood stasis, swelling and pain relief.

13) Tangshen \& largehead atractylodes rhizome. Tangshen is sweet and neutral in nature, and it tonifies the middle burner and augments Qi, strengthens the spleen and benefits the lungs. Largehead atractylodes rhizome is acrid, bitterand warm in nature, and belongs to the meridian of spleen, stomach and liver. Largehead atractylodes rhizome dries dampness and strengthens the spleen, expels wind and disperses cold. This herb combination can both tonify the middle burner and augments Qi, and dries dampness and strengthens the spleen.

\section{CONCLUSION}

The syndrome differentiation of DN is not fixed but dynamic development progress. In TCM theory, DN is quite complicated and is a combination of deficiency and excess. As we know, herbs are important carriers of TCM. Although lots of herbs are proven to have anti-inflammatory, antioxidative and anti-fibrotic effects, the usage is complicated as well. TCM has certain advantages in the prevention and treatment of $\mathrm{DN}$, which is affirmed by most TCM medical practitioners, but there is no uniform standard for syndrome differentiation and efficacy evaluation. TCM treatment of DN is better in the early and middle stages, especially in the early stage. In the middle and late stages of DN, single Chinese medicine cannot alleviate the condition and requires combination therapy of Western medicine. At present, the mechanism of prevention and treatment of DN by TCM is still unclear. The evidence-based medical studies for DN are limited and there is a lack of the multi-center large-scale clinical research as well.

TCM is more than "Artemisinin". We would better abandon prejudice and understand the advantages and disadvantages of both Chinese and Western medicine in the treatment of DN. We fully expect that the results of this research could shine valuable insight into TCM treatment of DN.

\section{Data Availability}

The data used to support the findings of this study are available from the corresponding author upon request.

\section{Conflicts}

The authors declare no conflicts of interest.

\section{REFERENCES}

1. Rossing P, Persson F, Frimodt-Møller M. Prognosis and treatment of diabetic nephropathy: Recent advances and perspectives. Nephrol Ther 2018; 14: S31-S37.

2. Himmelfarb J, Tuttle KR. New therapies for diabetic kidney disease. $N$ Engl J Med 2013; 369(26): 2549-2550.

3. Warren AM, Knudsen ST, Cooper ME. Diabetic nephropathy: An insight into molecular mechanisms and emerging therapies. Expert Opin Ther Targets 2019:1-13.

4. Aly MH, Arafat MA, Hussein OA, Elsaid HH, Abdel-Hammed AR. Study of Angiopoietin-2 and vascular endothelial growth factor as markers of diabetic nephropathy onset in Egyptians diabetic patients with non-albuminuric state. Diabetes Metab Syndr Clin Res Rev 2019; 13(2): 1623-1627.

5. Idzerda NM, Pena MJ, de Zeeuw D, Heerspink HJ. Future and Novel
Compounds in the Treatment of Diabetic Nephropathy. In: Diabetic Nephropathy. Springer 2019: 515-539.

6. Chen L. From China guidelines for type 2 diabetes to diagnosis and treatment of diabetic nephropathy. Zhongguo Shiyong Neike ZazhiChinese J Pract Intern Med 2009; 29(6): 513-516.

7. Pezzolesi MG, Krolewski AS. The Genetics of Diabetic Nephropathy. In: Diabetic Nephropathy. Springer 2019; 89-112.

8. Gross JL, De Azevedo MJ, Silveiro SP, Canani LH, Caramori ML, Zelmanovitz T. Diabetic nephropathy: Diagnosis, prevention, and treatment. Diabetes Care 2005; 28(1): 164-176.

9. Ou JY, Huang D, Wu YS, et al. A meta-analysis of randomized controlled trials of yiqi yangyin huoxue method in treating diabetic nephropathy. Evid Based Complement Alternat Med 2016; 2016.

10. Zhang L, Li Y, Guo X, et al. Text mining of the classical medical literature for medicines that show potential in diabetic nephropathy. Evid Based Complement Alternat Med 2014; 2014.

11. Zhang L, Mao W, Guo X, et al. Ginkgo biloba extract for patients with early diabetic nephropathy: A systematic review. Evid Based Complement Alternat Med 2013; 2013.

12. Li WL, Zheng HC, Bukuru J, De Kimpe N. Natural medicines used in the traditional Chinese medical system for therapy of diabetes mellitus. J Ethnopharmacol 2004; 92(1): 1-21.

13. Liu W, Liang X, Yang D. The Effects of Chinese Medicine on Activation of Wnt/ $\beta$-Catenin Signal Pathway under High Glucose Condition. Evid Based Complement Alternat Med 2015; 2015.

14. Pop-Busui R, Boulton AJ, Feldman EL, et al. Diabetic neuropathy: A position statement by the American Diabetes Association. Diabetes Care 2017; 40(1): 136-154.

15. Mogensen CE, Christensen CK, Vittinghus E. The stages in diabetic renal disease: With emphasis on the stage of incipient diabetic nephropathy. Diabetes 1983; 32(Supplement 2): 64-78.

16. Renhe L. Clinical Analysis on 568 Cases of Diabetic Nephropathy at Different Stages according to Treatment Based on Syndrome Differentiation. China J Tradit Chin Med Pharm 1994; 4.

17. Wenfeng Z. Standardization Research of Differentiation System of Symptoms and Signs and" Syndrome" in TCM. Gianjin J Tradit Chin Med 2002; (5).

18. Wenfeng Z. Study on Syndrome Factor Differentiation. Henan Tradit Chin Med 2009; 1.

19. Yang X, Peng W, Yue X. Syndrome differentiation and treatment of Taiyang disease in Shanghan Lun. Zhong Xi Yi Jie He Xue Bao 2009; 7(2): 171-174.

20. Jiang M, Lu C, Zhang C, et al. Syndrome differentiation in modern research of traditional Chinese medicine. J Ethnopharmacol 2012; 140(3): 634-642.

21. Xiao Y, Liu Y, Yu K, et al. The effect of chinese herbal medicine on albuminuria levels in patients with diabetic nephropathy: A systematic review and meta-analysis. Evid Based Complement Alternat Med 2013; 2013.

22. Ding Y, Li P, Wang Y, Zheng L, Zhao J. Analysis of experts' opinions on TCM syndrome differentiation about diabetic nephropathy by Delphi. China J Tradit Chin Med Pharm 2010; 10.

23. Xu HB, Jiang RH, Chen XZ, Li L. Chinese herbal medicine in treatment of diabetic peripheral neuropathy: A systematic review and meta-analysis. J Ethnopharmacol 2012; 143(2): 701-708.

24. Jinxi MXZDZ. A Study of TCM Syndrome Pattern in 265 Cases of Diabetic Renal Insufficiency. J New Chin Med 2007; 5.

25. Tzeng TF, Liou SS, Liu IM. The selected traditional chinese medicinal formulas for treating diabetic nephropathy: Perspective of modern science. J Tradit Complement Med 2013; 3(3): 152-158.

26. Elmarakby AA, Sullivan JC. Relationship between oxidative stress and 
inflammatory cytokines in diabetic nephropathy. Cardiovasc Ther 2012; 30(1): 49-59.

27. Locatelli F, Canaud B, Eckardt K-U, Stenvinkel P, Wanner C, Zoccali C. Oxidative stress in end-stage renal disease: An emerging threat to patient outcome. Nephrol Dial Transplant 2003; 18(7): 1272-1280.

28. Small DM, Coombes JS, Bennett N, Johnson DW, Gobe GC. Oxidative stress, anti-oxidant therapies and chronic kidney disease. Nephrology 2012; 17(4): 311-321.

29. Yongbo Q, Jin L, Fei W. Research development of chemical composition and pharmacological effects of milkvetch root. Chin J Conval Med 2011; 5.

30. Zhou L, Zuo Z, Chow MSS. Danshen: An overview of its chemistry, pharmacology, pharmacokinetics, and clinical use. J Clin Pharmacol 2005; 45(12): 1345-1359.

31. Li X, Lin J, Han W, et al. Antioxidant ability and mechanism of rhizoma Atractylodes macrocephala. Molecules 2012; 17(11): 13457-13472.

32. Mardani S, Nasri H, Rafieian-Kopaei M, Hajian S. Herbal medicine and diabetic kidney disease. J Nephropharmacology 2013; 2(1): 1-2.

33. Wang H, Li J, Yu L, Zhao Y, Ding W. Antifibrotic effect of the Chinese herbs, Astragalus mongholicus and Angelica sinensis, in a rat model of chronic puromycin aminonucleoside nephrosis. Life Sci 2004; 74(13): 1645-1658.

34. Zhong Y, Menon MC, Deng Y, Chen Y, He JC. Recent advances in traditional Chinese medicine for kidney disease. Am J Kidney Dis 2015; 66(3): 513-522.

35. Zeng CC, Liu X, Chen GR, et al. The molecular mechanism of rhein in diabetic nephropathy. Evid Based Complement Alternat Med 2014; 2014.

36. Zhao KJ, Dong TT, Tu PF, Song ZH, Lo CK, Tsim KW. Molecular genetic and chemical assessment of radix Angelica (Danggui) in China. J Agric Food Chem 2003; 51(9): 2576-2583.

37. Iizuka A, Iijima OT, Kondo $\mathrm{K}$, et al. Evaluation of Rhubarb using antioxidative activity as an index of pharmacological usefulness. J Ethnopharmacol 2004; 91(1): 89-94.

38. Sun Y, Guo T, Sui Y, Li F. Fingerprint analysis of Flos Carthami by capillary electrophoresis. J Chromatogr B 2003; 792(2): 147-152.

39. Zhao DD, Jiang LL, Li HY, Yan PF, Zhang YL. Chemical components and pharmacological activities of terpene natural products from the Genus Paeonia. Molecules 2016; 21(10): 1362.

40. Hao $\mathrm{C}, \mathrm{Wu} \mathrm{F}, \mathrm{Lu} \mathrm{L}$, et al. Chinese herbal medicine for diabetic peripheral neuropathy: An updated meta-analysis of 10 high-quality randomized controlled studies. PloS One 2013; 8(10): e76113.

41. Jia-cong C. Preliminary Demonstration Research of Chinese Medicine Heterophylly Falsestarwort Root Edible Development. Guide China Med 2011; 9.

42. Yu SJ, Tseng J. Fu-Ling, a Chinese herbal drug, modulates cytokine secretion by human peripheral blood monocytes. Int J Immunopharmacol 1996; 18(1): 37-44.

43. Zhu Q, Zheng G, Zhang D. Study on antitumor effect and mechanism of extract of largehead atractylodes rhizome. J Shandong Univ Tradit Chin Med 2006; 1.

44. Wang M, Yan H. Extraction of the active constituents from common yam rhizome. Shanxi Chem Ind 2008; 6. 